\title{
Differential Detection of Enterovirus and Herpes Simplex Virus in Cerebrospinal Fluid by Real-Time RT-PCR
}

\author{
Brenda Sarquiz-Martínez ${ }^{\mathrm{a}, \mathrm{c}}$ César R. González-Bonilla ${ }^{\mathrm{b}}$ \\ Clara Esperanza Santacruz-Tinoco ${ }^{a}$ José E. Muñoz-Medina ${ }^{a}$ \\ Héctor D. Pardavé-Alejandre ${ }^{a}$ Elizabeth Barbosa-Cabrera ${ }^{c}$ \\ José Ernesto Ramírez-González ${ }^{\mathrm{d}}$ José Alberto Díaz-Quiñonez ${ }^{\mathrm{d}, \mathrm{e}}$ \\ a Laboratorio Central de Epidemiología and ' ${ }^{b}$ División de Laboratorios de Vigilancia e Investigación Epidemiológica, \\ Instituto Mexicano de Seguridad Social (IMSS), ' Sección de Estudios de Posgrado e Investigación, Escuela Nacional \\ de Medicina, Instituto Politécnico Nacional, d Instituto de Diagnóstico y Referencia Epidemiológicos (InDRE), \\ "Dr. Manuel Martínez Báez," and "Division de Estudios de Posgrado Facultad de Medicina, Universidad Nacional \\ Autónoma de México, Mexico City, México
}

\section{Keywords}

Enterovirus · Herpes simplex virus · Real-time RT-PCR . Cerebrospinal fluid samples

\begin{abstract}
Background: Enterovirus (EV) and herpes simplex virus 1 and 2 (HSV1 and HSV2) are the main etiologic agents of central nervous system infections. Early laboratory confirmation of these infections is performed by viral culture of the cerebrospinal fluid (CSF), or the detection of specific antibodies in serum (e.g., HSV). The sensitivity of viral culture ranges from 65 to $75 \%$, with a recovery time varying from 3 to 10 days. Serological tests are faster and easy to carry out, but they exhibit cross-reactivity between HSV1 and HSV2. Although molecular techniques are more sensitive (sensitivity $>95 \%$ ), they are more expensive and highly susceptible to cross-contamination. Methods: A real-time RT-PCR for the detection of EV, HSV1, and HSV2 was compared with end-
\end{abstract}

\section{KARGER}

(C) 2017 S. Karger AG, Basel point nested PCR. Results: We tested 87 CSF samples of patients with a clinical diagnosis of viral meningitis or encephalitis. Fourteen samples were found to be positive by RT-PCR, but only 8 were positive by end-point PCR. The RT-PCR showed a specificity range of $94-100 \%$, the negative predictive value was $100 \%$, and the positive predictive value was 62,100 , and $28 \%$ for HSV1, HSV2, and EV, respectively. Conclusion: Real-time RT-PCR detected EV, HSV1, and HSV2 with a higher sensitivity and specificity than end-point nested RTPCR.

(c) 2017 S. Karger AG, Basel

Enterovirus (EV) and herpes simplex virus 1 and 2 (HSV1 and HSV2) are the main etiologic agents of central nervous system (CNS) infections [1-3]. The US Centers for Disease Control (CDC) report approximately 20,000 cases of meningoencephalitis annually. In Mexico, the Mexican Institute for Social Security (IMSS) reported 330 
Table 1. Primers and probes used for end-point PCR and real-time RT-PCR assays

\begin{tabular}{|c|c|c|c|c|c|}
\hline Agent & Primer/probe & Sequence $\left(5^{\prime}-3^{\prime}\right)$ & Region target & $\operatorname{Tm}^{\mathrm{b}},{ }^{\circ} \mathrm{C}$ & Position $^{\mathrm{a}}$ \\
\hline \multicolumn{6}{|c|}{ End-point PCR } \\
\hline \multirow[t]{3}{*}{$\mathrm{EV}^{\mathrm{c}}$} & EV1 (sense) & CAAGCACTTCTGTTTCCCCGG & \multirow[t]{3}{*}{$5^{\prime} \mathrm{UTR}$} & 58.7 & $162-182$ \\
\hline & EV2 (sense) & TCCTCCGGCCCCTGAATGCG & & 64.8 & $443-462$ \\
\hline & EV3 (antisense) & ATTGTCACCATAAGCAGCCA & & 54.6 & $577-596$ \\
\hline \multirow[t]{4}{*}{$\mathrm{HSV}^{\mathrm{d}}$} & HSV 1 ext Fw & ATCACGGTAGCCCGGCCGTGTGACA & \multirow[t]{4}{*}{ glycoprotein D gene } & 67.9 & $23-47$ \\
\hline & HSV 1 ext Rev & CATACCGGAACGCACCACACAA & & 60 & $222-243$ \\
\hline & HSV 1 int Fw & CCATACCGACCACACCGACGA & & 61.2 & $55-75$ \\
\hline & HSV 1 int Rev & GGTAGTTGGTCGTTCGCGCTGAA & & 61.6 & $170-192$ \\
\hline \multirow[t]{4}{*}{$\mathrm{HSV}^{\mathrm{d}}$} & HSV 2 ext Fw & TCAGCCCATCCTCCTTCGGCAGTA & \multirow[t]{4}{*}{ glycoprotein G gene } & 63.7 & $363-386$ \\
\hline & HSV 2 ext Rev & TCTACCCACAACAGACCCACG & & 58.9 & $567-587$ \\
\hline & HSV 2 int Fw & AGACGTGCGGGTCGTACACG & & 62 & $422-441$ \\
\hline & HSV 2 int Rev & CGCGCGGTCCCAGATCGGCA & & 67.7 & $503-521$ \\
\hline \multicolumn{6}{|c|}{ Real-time RT-PCR } \\
\hline \multirow[t]{3}{*}{$\mathrm{EV}^{\mathrm{e}}$} & EV1 (sense) & GGCCCCTGAATGCGGCTAATCC & \multirow[t]{3}{*}{$5^{\prime} \mathrm{UTR}$} & 62.9 & $449-470$ \\
\hline & EV2 (antisense) & GCGATTGTCACCATWAGCAGYCA & & 58.8 & $577-599$ \\
\hline & EV P (probe) & FAM-CCGACTACTTTGGGWGTCCGTGT-BBQ & & 63.9 & $537-559$ \\
\hline \multirow[t]{3}{*}{$H S V 1^{f}$} & HSV1 Fw (sense) & CGGCCGTGTGACACTATCG & \multirow[t]{3}{*}{ glycoprotein D gene } & 58.3 & $35-53$ \\
\hline & HSV1 Rev (antisense) & CTCGTAAAATGGCCCСТCC & & 55.7 & $87-105$ \\
\hline & HSV1 P (probe) & VIC-CCATACCGACCACACCGACGAAC-BBQ & & 68.7 & $55-78$ \\
\hline \multirow[t]{3}{*}{$\mathrm{HSV} 2^{\mathrm{f}}$} & HSV2 Fw (sense) & CGCTCTCGTAAATGCTTCCCT & \multirow[t]{3}{*}{ glycoprotein G gene } & 57.2 & $477-497$ \\
\hline & HSV2 Rev (antisense) & TCTACCCACAACAGACCCACG & & 58.9 & $567-587$ \\
\hline & HSV2 P (probe) & CY5-CGCGGAGACATTCGAGTACCAGATCG-BBQ & & 67.9 & $522-547$ \\
\hline \multirow[t]{3}{*}{$\mathrm{RP}^{\mathrm{g}}$} & RP Fw (sense) & AGATTTGGACCTGCGAGCG & \multirow[t]{3}{*}{ RNase P } & 57.9 & $50-68$ \\
\hline & RP Rev (antisense) & GAGCGGCTGTCTCCACAAGT & & 59.8 & $689-708$ \\
\hline & RP P (probe) & FAM-TTCTGACCTGAAGGCTCTGCGCG-BHQ-1 & & 63.6 & $71-93$ \\
\hline
\end{tabular}

Primers and probes used for end-point PCR and real-time RT-PCR for the detection of enterovirus (EV), herpes simplex virus 1 and 2 (HSV1 and HSV2), and the internal control ribonuclease P (RP). With end-point PCR, for EV amplification, primers EV1-EV3 were used for the 1st round, and EV2-EV3 for the 2nd round. For HSV1 amplification, primers HSV1-ext-Fw and HSV1-ext-Rev were used for the 1st round, and HSV1-int-Fw and HSV1-int-Rev for the 2nd round. For HSV2 amplification, primers HSV2-ext-Fw and HSV2Rev were used for the 1st round, and HSV2-int-Fw and HSV2-int-Rev for the 2nd round. Fw, forward; Rev, reverse; ext, external; int, internal.

${ }^{a}$ Virus sequences were based on the following GenBank accession Nos.: EV: NC_002058.3 for poliovirus; HSV1: J02217.1; HSV2: AJ303204.1.

${ }^{\mathrm{b}}$ Melting temperature, estimated by IDT for primers and TIB MOLBIOL for probes.

${ }^{c}$ The nested PCR EV primers were previously reported [14, 27].

$\mathrm{d}$ The nested PCR HSV1/2 primers were previously reported $[12,13]$.

e The real-time RT-PCR EV primers and probe were previously reported [25], but they were labeled with $3^{\prime} \mathrm{BBQ}$.

${ }^{\mathrm{f}}$ The real-time HSV $1 / 2$ primers and probes were previously reported [9] but they were labeled with $5^{\prime} \mathrm{VIC}-3^{\prime} \mathrm{BBQ}$ and $5^{\prime} \mathrm{CY} 5-3^{\prime} \mathrm{BBQ}$, respectively.

g RNase P sequences were based on GenBank accession No. XM_011539123.1.

cases in 2014 [4]. Early laboratory diagnosis of CNS infections is performed by viral culture of the cerebrospinal fluid (CSF) for EV, or the detection of specific antibodies in serum for HSV. However, the viral recovery rate is low, and not all serotypes replicate efficiently in culture. Therefore, the sensitivity of viral culture ranges between 65 and $75 \%$, with a recovery time ranging from 3 to 10 days $[5,6]$. Moreover, serological diagnostic tests for
HSV infections have cross-reactivity between HSV1 and HSV2 due to the high homology of their antigens. Recently, molecular methods have become the reference techniques for the diagnosis of CNS viral infections due to their high sensitivity (>95\%) [7-9]. Currently, assays based on real-time RT-PCR using TaqMan ${ }^{\circledR}$ probes are highly sensitive and specific, and also reduce detection times; this improves the diagnosis and guides the specific 
treatment, reducing the length and cost of hospitalization $[10,11]$. However, it is difficult to simultaneously detect the large number of causative agents of CNS infections through a multiplex single assay. The purpose of this study was to develop a real-time RT-PCR test for the differential detection of these viruses, and to compare it with an end-point PCR, while monitoring the integrity of the sample through an internal control, ribonuclease $P$ (RNase P, RP), in an individual reaction in each round of amplification in order to provide a fast and reliable diagnosis of viral CNS infections.

Eighty-seven CSF samples were obtained from hospitalized patients with a clinical diagnosis of meningitis, encephalitis, acute flaccid paralysis (AFP) or Guillain-Barré syndrome. Samples were collected between 2010 and 2014 from 8 different states of Mexico from the IMSS epidemiological surveillance system, which complies with all the local regulations so that no additional approval was required. Genetic material from the 87 CSF samples stored at $-70^{\circ} \mathrm{C}$ was extracted automatically using a Magna Pure LC 2.0 Instrument (Roche Diagnostics, Basel, Switzerland). The purified product was obtained in $60 \mu \mathrm{L}$ of RNase-free elution solution and stored at $-70^{\circ} \mathrm{C}$ until use. As positive controls, different cDNA-positive plasmids were constructed by cloning the amplified product obtained from the first round of each nested RT-PCR from the commercial available viruses (AmpliRun, Vircell S.L., Spain). The primers and TaqMan ${ }^{\circledR}$ primers and probes for the detection of EV, HSV1, or HSV2 by endpoint nested RT-PCR or real-time RT-PCR were used as reported, and are summarized in Table 1 [12-14]. The probes of the 3 viruses were modified at the $5^{\prime}$ and $3^{\prime}$ ends with fluorophores and their corresponding quenchers. The specificity and performance of all primers and probes used in this study were evaluated by BLAST analysis and using Primer Express v3.0 (Thermo Fisher Scientific Inc., CA, USA). The end-point PCR products were run in a $1 \%$ agarose gel stained with GelRed ${ }^{\mathrm{TM}}$ (Biotium, CA, USA). Positive samples were prepared for sequencing. Positive and negative controls were included in each end-point nested RT-PCR run. The reaction mix for the real-time RT-PCR consisted of 20 pmol of HSV1 or HSV2 primers, 30 pmol of EV primers, and 10-15 pmol of the corresponding probe. The assay was conducted in a 7500 Fast ThermoCycler (Applied Biosystems, Life Technologies, CA, USA) under the following conditions; reverse transcription at $50^{\circ} \mathrm{C}$ for $30 \mathrm{~min}$, activation of Taq DNA polymerase at $95^{\circ} \mathrm{C}$ for $10 \mathrm{~min}$, followed by 45 cycles of $95^{\circ} \mathrm{C}$ $15 \mathrm{~s}$, and $60^{\circ} \mathrm{C}$ for $45 \mathrm{~s}$. Fluorescence data were reported at the end of each cycle. Negative controls contained all
Table 2. End-point PCR and real-time RT-PCR results in 87 CSF samples

\begin{tabular}{rlll}
\hline Sample & Year & Nested PCR & Real-time RT-PCR \\
\hline 1 & 2010 & HSV2 & HSV2 \\
2 & 2010 & - & HSV1 \\
3 & 2010 & - & HSV1 \\
4 & 2010 & - & HSV1 \\
5 & 2011 & HSV2 & HSV2 \\
6 & 2011 & EV & EV \\
7 & 2011 & HSV1 & HSV1 \\
8 & 2011 & EV & EV \\
9 & 2012 & HSV1 + HSV2 & EV + HSV1 + HSV2 \\
10 & 2012 & HSV1 & HSV1 + HSV2 \\
11 & 2012 & HSV1 & EV + HSV1 \\
12 & 2012 & - & EV \\
13 & 2013 & HSV2 & EV + HSV2 \\
14 & 2014 & HSV1 + HSV2 & EV + HSV1 + HSV2 \\
\hline
\end{tabular}

Only 10 samples were positive using end-point PCR and 14 were positive with real-time RT-PCR. Interestingly, 5 were identically detected (samples 1 and 5-8). Higher sensitivity was observed when real-time PCR was used, as samples 2, 3, 4, and 12 were not even positive using the reference protocol of nested PCR and additional positive detection was found in samples 9-11, 13, and 14 . HSV1, herpes simplex virus type 1; HSV2, herpes simplex virus type 2 ; EV, enterovirus.

the reagents, with the exception of the nucleic acids. All mixtures were prepared using the SuperScript III Platinum One-Step Quantitative RT-PCR System (Invitrogen, Life Technologies, CA, USA).

The analytical sensitivity and limit of detection (LOD) of the real-time RT-PCR for EV, HSV1, and HSV2 were evaluated using 10-fold serial dilutions of the linearized positive controls $\mathrm{pEV}$, pgD-HSV1, and pgG-HSV2 in DNase- and RNase-free water over a range of $1 \times 10^{8}$ to 10 copies/ $\mu \mathrm{L}$. The LOD for each target was defined as the lowest dilution detected of serially diluted positive controls. The analytical specificity of the assay was determined by performing several cross-reactivity tests in EV, HSV1, HSV2, and other viruses including influenza H1N1, dengue serotypes 1-4, and measles, and also against 15 controls of neurotropic viruses and bacteria, including echovirus, parvovirus, adenovirus, Haemophilus influenzae, rubella, varicella, coxsackievirus, Western equine encephalitis (WEE), Venezuelan equine encephalitis (VEE), Staphylococcus aureus, Streptococcus agalactiae, Streptococcus viridans, Streptococcus pneumoniae, Streptococcus pyogenes, and Neisseria meningitidis, obtained from the InDRE (data not shown).
Sarquiz-Martínez et al. 


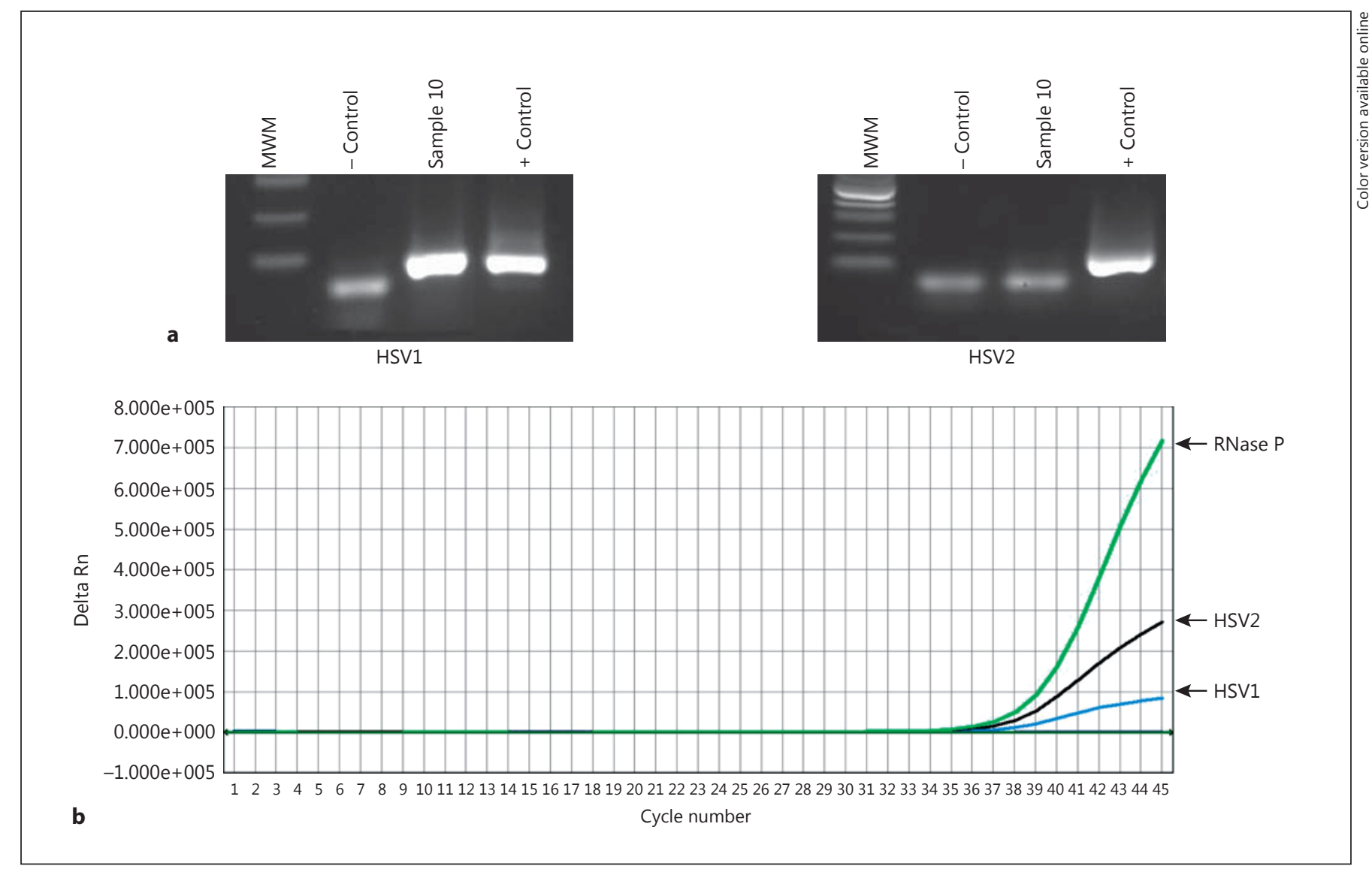

Fig. 1. An example of differences in sensitivity of nested PCR (a) and real-time RT-PCR (b). The assay was carried out for HSV1 and HSV2 using sample 10 (Table 1). a Sample 10 was positive for HSV1 and negative for HSV2. MWM, molecular-weight marker;

The test had a LOD of 10 copies/ $\mu \mathrm{L}$ for EV with a mean (threshold cycle) Ct interassay value of 37.44, a standard deviation (SD) of 1.13 cycles, and a coefficient of variation $(\mathrm{CV})$ of $3 \%$. The LOD for HSV1 was also 10 copies $/ \mu \mathrm{L}$, with a $\mathrm{Ct}$ of $36.89(\mathrm{SD}=0.54 ; \mathrm{CV}=1.46 \%)$. Finally, the LOD for HSV2 was 10 copies/ $\mu \mathrm{L}$, with a Ct of 35.13 (SD = 1.29; CV $=3.67 \%)$. Using the 7500 Fast System ${ }^{\circledR}$ software v14.0, a linear regression was generated by plotting the $\mathrm{Ct}$ values of different dilutions of the positive controls of the 3 viruses during amplification on a logarithmic scale. The values reflected efficiencies of between 90 and $100 \%$ for the 3 viruses, with a slope of -3.38 and $R^{2}=0.9950$ for EV, -3.21 and $R^{2}=0.9955$ for HSV1, and -3.39 and $R^{2}=$ 0.9997 for HSV2. These values indicated good reproducibility of the test. It is important to note that the primers and $\mathrm{EV}$ probe are directed to a conserved and untranslated region of the genus Enterovirus.

Detection of EV and HSV by Real-Time RT-PCR
-/+ control, negative/positive control. b Simultaneous real-time RT-PCR of sample 10 shows clearly that it is indeed a coinfection of both HSV1 and HSV2. The line representing the internal control, RNase P, shows the integrity of the sample.

Thirty-four out of the 87 CSF samples analyzed corresponded to men and 53 to women, and 9 of these were from pediatric patients. The presumptive diagnosis was meningitis, AFP, or Guillain-Barré syndrome, and only 4 were referred with the specific diagnosis of viral encephalitis. The real-time RT-PCR revealed 14 positive samples: 4 were positive for HSV1, 1 for HSV2, 3 for EV, and 5 exhibited coinfection, i.e., EV + HSV1/2 or HSV 1 + HSV2. Ten positive results were obtained with the end-point nested PCR: 1 for HSV1, 2 for HSV2, 2 for EV, and 3 coinfections; this correlated with the real-time RTPCR (Table 2). It is important to note that coinfections of viruses in CSF have been reported previously [15]. The remaining 73 samples were negative when applying both techniques. All the positive samples obtained by the real-time RT-PCR were subject to sequencing, and the presence of viruses was confirmed as detected. The re- 
sults showed the presence of viruses as detected in the real-time assay. Figure 1 shows the results of sample 10. Only HSV1 was detected by end-point nested RT-PCR, but a HSV1-HSV2 coinfection was detected by real-time RT-PCR. The data indicated that the real-time RT-PCR, compared to the end-point PCR, had a specificity of 96, 100 , and $94 \%$ for HSV1, HSV2, and EV, respectively; a sensitivity of $100 \%$ for all 3 viruses; a positive predictive value (PPV) of 62,100 , and $28 \%$ for HSV1, HSV2, and $\mathrm{EV}$, respectively; and a negative predictive value (NPV) of $100 \%$ for all 3 viruses. Since this evaluation, real-time RT-PCR has been used in the Central Laboratory of Epidemiology of the IMSS, as part of the confirmatory diagnostic algorithm of neural infections and AFP (of one or both limbs with decreased or impaired stretch reflex, normal sensitive and cognitive functions, without noticeable cause). Before 2016, the main infectious causes of AFP included Campylobacter jejuni and Enterovirus. Although polioviruses are not circulating in the country, the national epidemiological survey system instructs that they have to be looked for in children under 15 years of age. Notably, the Zika virus is the main cause of AFP at the present time. The assay is carried out in CSF and stool samples.

Since June 2016, 173 samples of CSF have been analyzed, 122 of which have been negative, and 8 positive for EV, 5 for HSV1, and 21 for HSV2. There have been 3 coinfections of EV + HSV2 and 2 coinfections of HSV 1 + HSV2. Only 12 have been discarded because they did not meet the quality required.

This study describes the development of an in-house real-time RT-PCR test using TaqMan ${ }^{\circledR}$ probes to detect EV, HSV1, and HSV2 in CSF samples. The technique is based on the development of 4 independent reactions that simultaneously amplify these viruses and the RP and viral reference controls, decreasing the risk of nonspecificity, and reducing the execution time compared to the reference end-point test. Although the test was not intended to provide viral load quantification, it can yield results on the presence/absence of the viruses most involved in neuroinfections and even detect coinfections. The reference end-point test was developed according to published protocols [12-14], but in the case of HSV2, the external reverse primer was switched for the external real-time primer to generate a larger fragment for the construction of the in-house internal control.

The purpose of performing our assay in separate reactions is to achieve specific and simultaneous detection, without the risk of cross-contamination. Using this method, $100 \%$ sensitivity was obtained for the 3 viruses, and we observed no cross-reactions with any of the viruses analyzed; additionally, specificities with high values were achieved (EV: 96\%, HSV1: 100\%, and HSV2: 94\%), similar to those reported with the end-point and other real-time techniques, and even higher than the specificity achieved with other commercial kits $[7,11$, 16-21]. These results indicate that the sequences used for the primers and probes are specific; in the case of EV, the primers allow the identification of all viruses grouped in the genus, as the target sequence is highly conserved among its members; in the case of HSV1 and HSV2, as the primers are aimed at 2 different targets, this protocol can achieve differential diagnosis between these 2 viruses, without observing the cross-reactions that have been reported in other studies that use different areas of the same target [22-24]. The LOD for the 3 viruses were all 10 copies $/ \mu \mathrm{L}$, with very similar Ct values of $36.89,35.13$, and 37.44 for HSV1, HSV2, and EV, respectively. In previous studies on EV, a range of 30-37 for the Ct values has been reported to determine that a sample is positive $[8,11,25]$; however, these values can vary, as they depend on both the quality of the standard used and the viral load in the CSF. Similarly, the results obtained for the HSV1 and HSV2 amplifications showed the expected LOD; however, it has been frequently reported that samples with low viral loads yield Ct values of $>38[2,9$, 21]. In our case, the highest $C t$ value in herpesvirus-containing samples was 36.89 for HSV1 in the minimum dilution.

The NPV was $100 \%$ for all 3 viruses, but the PPV of EV and HSV1 was lower (62 and 28\%, respectively), which seems to indicate the presence of false-positives when comparing our test against the reference. However, upon subjecting positive samples to sequencing analysis, the presence of the viruses involved was verified, indicating that our results were the product of the increased sensitivity of real-time RT-PCR over end-point PCR. It should be mentioned that some samples amplified late, especially those positive for EV. This could be due to several factors, such as the storage period. The reproducibility of the assay was demonstrated by the consistency of the 3 reactions in 5 replicates with plasmid-positive controls. Their Ct values and the CV indicated that the data behaved homogeneously in each dilution, with values being located within an acceptable range $(0.33-2.37 \%)$ for diagnostic purposes [11, 21]. Unlike many proposed real-time techniques for the detection of the viruses studied here, our test used an internal control for each sample in each round of amplification, which enabled verification of the integrity of the
122

Intervirology 2017;60:118-124

DOI: $10.1159 / 000480508$
Sarquiz-Martínez et al. 
sample and the presence of contamination. It has been reported that one of the disadvantages of using an internal control in molecular techniques is competition during the reaction with the viruses to be detected. Here, the reactions were performed independently, with genetic material for each reaction, thereby decreasing any risk of competition for reactants.

The most common virus found in the samples was HSV1, either independently or in association with other viruses in adult patients. The close relationship between neuroinfection and immunosuppression could also be confirmed, as little more than $50 \%$ of the positive samples were from patients with this immunological profile. These findings coincide with those reported in the literature and in several studies on the detection of herpesviruses $[1,10,12]$. While it is true that the test proposed in this study is purely qualitative, the advantage of a simultaneous differential diagnosis lies in the possibility of helping direct treatment more specifically, allowing for shorter hospitalization and reduced costs for both the patients and the health institution. At the epidemiological level, this assay provides an option that would help contribute to the reduction of the underreporting of these conditions. It is necessary to conduct more studies with respect to the relationship of viral load with severity of condition or EV genotype; it would also be advantageous to develop a differential algorithm for bacteria and viruses to foster a more comprehensive strategy in the diagnosis and treatment of infections of the CNS.

\section{Conclusions}

A real-time RT-PCR test was developed for the confirmatory and differential diagnosis of viral neuroinfections from CSF samples. The identification of the viral etiology of the neurologic infections can contribute to better medical treatment for patients, minimizing the costs of hospitalization, hastening recovery, and sustainably contributing to the epidemiological data of surveying entities. This method can be enriched by further study and by incorporating the same technique for the detection of other viruses of neurological significance. This could include protocols for their quantification or even designing an algorithm for neurological infections by viruses and bacteria with a higher incidence and medical importance. In this way, various types of samples could be evaluated; this could decrease the use of invasive sampling techniques and foster a better understanding (from a different perspective) of the pathogenesis of various infectious agents in the CNS.

\section{Acknowledgements}

The authors thank Irma López, Edith Pérez, Noé Escobar, and Joanna Ortíz from InDRE for their support in sequencing and bioinformatics techniques. This study was sponsored by the Health Research Fund of IMSS, project No. 2011-785-006. B.S.-M. received a scholarship from Conacyt, registration No. 166567. Part of this work was taken from the PhD thesis of B.S.-M.

\section{Disclosure Statement}

The authors declare that they have no conflict of interest.

\section{References}

1 Chadwick DR: Viral meningitis. Br Med Bull 2006; 10:75-76.

2 Dupuis M, Hull R, Wang H, Nattanmai S, Glasheen B, Fusco H, Dzigua L, Markey K, Tavakoli NP: Molecular detection of viral causes of encephalitis and meningitis in New York State. J Med Virol 2011;83:2172-2218.

3 Steiner I, Budka H, Chaudhuri A, Koskiniemi M, Sainio K, Salonen O, Kennedy PG: Viral encephalitis: a review of diagnostic methods and guidelines for management. Eur J Neurol 2005;12:331-343.

4 SSA: Sistema Único Automatizado de Vigilancia Epidemiológica, SSA, 2014. http:// www.sinave.gob.mx/SUAVE/Inicio_sesion. aspx.
5 Ashok V, Solbring M: Infections of the nervous system; in Bradley W, Daroff R, Fenichel G, Jankovic J (eds): Neurology Clinical Practice: Principles of Diagnosis and Management. Philadelphia, Elsevier, 2004, pp 14551495.

6 Rotbart H: Enteroviral infections of the central nervous system. Clin Infect Dis 1995;20: 971-981.

7 Leveque N, Haecke AV, Renois F, Boutolleau D, Talmud D, Andreoletti L: Rapid virological diagnosis of central nervous system infections by use of a multiplex reverse transcriptionPCR DNA microarray. J Clin Microbiol 2011; 49:3874-3879.
8 Verstrepen WA, Kuhn S, Kockx MM, Van De Vyvere ME, Mertens AH: Rapid detection of enterovirus RNA in cerebrospinal fluid specimens with a novel single-tube real-time reverse transcription-PCR assay. J Clin Microbiol 2001;39:4093-4096.

9 Weidmann M, Meyer-König U, Hufert FT: Rapid detection of Herpes simplex virus and Varicella zoster virus infections by real-time PCR. J Clin Microbiol 2003;41:1565-1568.

10 Pruitt A: Infections of the nervous system. Neurol Clin 1998;16:419-447.

11 Volle R, Nourrisson C, Mirand A, Regagnon C, Chambon M, Henquell C, Bailly JL, PeigueLafeuille H, Archimbaud C: Quantitative realtime RT-PCR assay for research studies on enterovirus infections in the central nervous system. J Virol Methods 2012;185:142-148. 
12 Aurelius E, Johansson B, Sköldenberg B, Forsgren $\mathrm{M}$ : Encephalitis in immunocompetent patients due to Herpes simplex virus type 1 or 2 as determined by type-specific polymerase chain reaction and antibody assays of cerebrospinal fluid. J Med Virol 1993;39:179-186.

13 Aurelius E, Johansson B, Sköldenberg B, Staland A, Forsgren M: Rapid diagnosis of Herpes simplex encephalitis by nested polymerase chain reaction assay of cerebrospinal fluid. Lancet 1991;337:189-192

14 Zoll GJ, Melchers W, Kopecka H, Jambroes G, Van der Poel H, Galama J: General primermediated polymerase chain reaction for detection of enteroviruses: application for diagnostic routine and persistent infections. J Clin Microbiol 1992;30:160-165.

15 Mancuso R, Hemis A, Cavarretta R, Caputo D, Calabrese E, Nemni R, Ferrante P, Delbue $S$, Clerici M: Detection of viral DNA sequences in the cerebrospinal fluid of patients with multiple sclerosis. J Med Virol 2010;82:10511057.

16 Cabrerizo M, Calvo C, Rabella N, Muñoz-Almagro C, del Amo E, Pérez-Ruiz M, Sanbonmatsu-Gámez S, Moreno-Docón A, Otero A, Trallero G: Design and validation of real-time RT-PCR for the simultaneous detection of enteroviruses and parechoviruses in clinical samples. J Virol Methods 2014;208:125-128.
17 de Crom SC, Obihara CC, van Loon AM, Argilagos-Alvarez AA, Peeters MF, van Furth AM, Rossen JW: Detection of enterovirus RNA in cerebrospinal fluid: comparison of two molecular assays. J Virol Methods 2012; 179:104-107.

18 Heaton PR, Espy MJ, Binnicker MJ: Evaluation of 2 multiplex real-time PCR assays for the detection of HSV1/2 and Varicella zoster virus directly from clinical samples. Diagn Microbiol Infect Dis 2015;81:169-170.

19 Kuypers J, Boughton G, Chung J, Hussey L, Huang ML, Cook L: Comparison of the Simplexa HSV1 and 2 Direct kit and laboratorydeveloped real-time PCR assays for Herpes simplex virus detection. J Clin Virol 2015;62: 103-105.

20 Ninove L, Nougairede A, Gazin C, Zandotti C, Drancourt M, de Lamballerie X, Charrel $\mathrm{RN}$ : Comparative detection of enterovirus RNA in cerebrospinal fluid: GeneXpert system vs. real-time RT-PCR assay. J Clin Microbiol Infect 2011;17:1890-1894.

21 Pillet S, Verhoeven PO, Epercieux A, Bourlet $\mathrm{T}$ : Development and validation of a laboratory-developed multiplex real-time PCR assay on the BD Max system for detection of Herpes simplex virus and Varicella zoster virus DNA in various clinical specimens. J Clin Microbiol 2015;53:1921-1926.

22 McIver CJ, Jacques CF, Chow SS, Munro SC, Scott GM, Roberts JA, Craig ME, Rawlinson WD: Development of multiplex PCRs for detection of common viral pathogens and agents of congenital infections. J Clin Microbiol 2005;43:5102-5110.
23 Read SJ, Kurtz JB: Laboratory diagnosis of common viral infections of the central nervous system by using a single multiplex PCR screening assay. J Clin Microbiol 1999;37: 1352-1355.

24 Read SJ, Mitchell JL, Fink, CG: LightCycler multiplex PCR for the laboratory diagnosis of common viral infections of the central nervous system. J Clin Microbiol 2001;39:30563059.

25 Oberste MS, Peñaranda S, Rogers SL, Henderson E, Nix WA: Comparative evaluation of Taqman real-time PCR and semi-nested VP1 PCR for detection of enteroviruses in clinical specimens. J Clin Virol 2010;49:73-74.

26 Messacar K, Breazeale G, Wei Q, Robinson CC, Dominguez SR: Epidemiology and clinical characteristics of infants with human Parechovirus or human Herpes virus-6 detected in cerebrospinal fluid tested for Enterovirus or Herpes simplex virus. J Med Virol 2015; 5:829-835.

27 Zoll GJ, Melchers WJ, Kopecka H, Jambroes G, Van der Poel HJ, Galama JM: General primer-mediated polymerase chain reaction for detection of enteroviruses: application for diagnostic routine and persistent infections. J Clin Microbiol 1992;30:160-165. 